\title{
rVT
}

استخدام مؤشر الطاقة البيوميكانيكية والسعرات الحرارية كمحددات لاجتياز اختبارات القبول بقسم التربية البدنية وعلوم الحركة

\section{بجامعة القصيم}

"د/هانبي عبد العزبز ابراهيم

تعتبر الاختبارات البدنية هي المعيار الأول في القبول بكليات وأقسـام

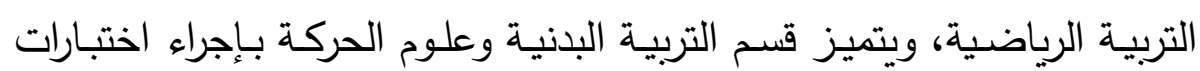

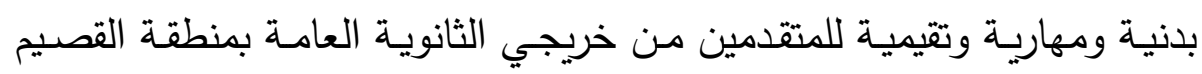
بالمملكة العربية السعودية.

ويمتاز القسم بأن الطالب الذي يرغب في الالتحاق بـه يجب عليه أولاً أن يجتاز العديد من الاختبارات وهي كالتالي: نظام اختبارات القبول بقسم التربية البذنية بكلية التربية: الغزرض من إجراء الاختبارات:

- التأكد من سلامة الطالب الصحية وفقاً للكشف الطبي. - اختيار الطلاب اللائقين للدراسة بقسم التربية البدنية بكلية التربية.

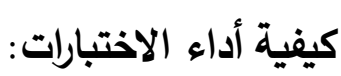

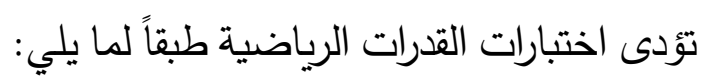
اختبارات المهارة في نوع النشاط الرياضي (المهارة): - الدرجة النهائية للمهارة • عدرجة. - الدرجة الأدنى للمهارة 7 (ادرجة.

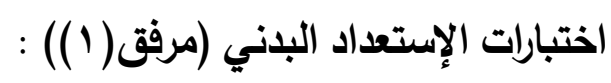

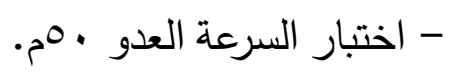

" أستاذ مساعد بقسم التدريب الرياضي وعلوم الحركة، كلية التربية الرياضية ببورسعيد، مجالة أسيوط لعلوم وفنون التربية الرياضية

جامعة بورسعيد. 
- اختبار تحمل القوة ثني الذراعين من وضع الإنبطاح لمدة واحد دقيقة. - اختبار قدرة الوثب إماماً. - اختبار الجري الزجزاجى بين الأقماع. - ثنى الجذع أماماً من الجلوس طولاً.

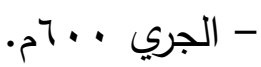

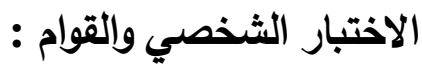
- اختبار القوام (الكثف عن الانحرافات القومية المختلفة).

- اختبار المقابلة الشخصية (نطق - سمع - صوت - مظهر - معلومات) ويعتبر كل من الثخل والطاقة والقدرة من أهم المتغيرات البيوديناميكية

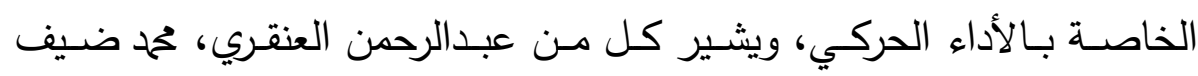

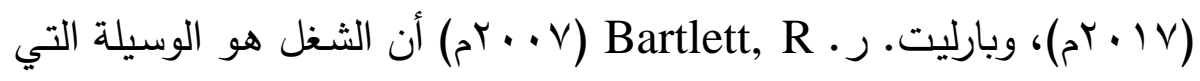
تنتقل بها الطاقة من جسم إلى آخر ، بينما تعرف الطاقة بأنها القدرة على بذل فئل

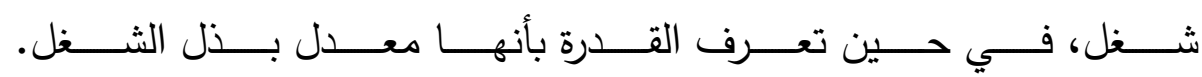
$(\varepsilon \mid r: \tau) ،(1 \leq r-1$ |r $(\varepsilon: \varepsilon)$ ومما سبق يتضح أن إقتران كل من الشغل والطاقة والقدرة يعطي دلالة بإرتباطها مفهوماً وتعريفاً وقانوناً.

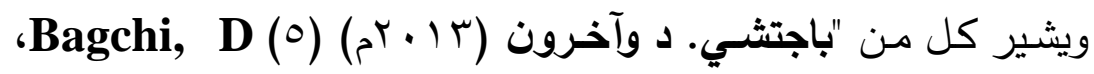

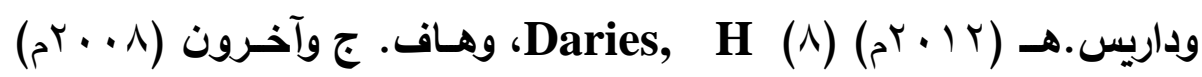
(9aff, G. (9) أن أنظمـة الطاقـة في جسم الإنسـان تنقسم إلى نظـامين

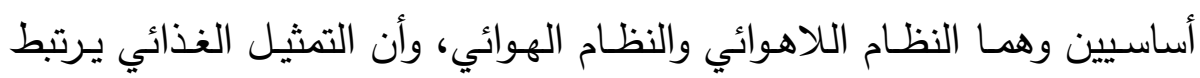
ارتباطاً كبيراً بقدرة العضلات على الانقباض وبالتالي بالقدرة على بذل شغل.

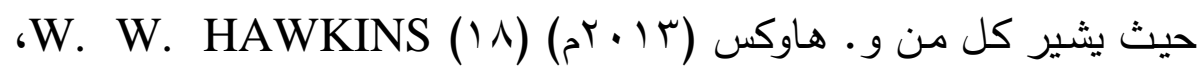

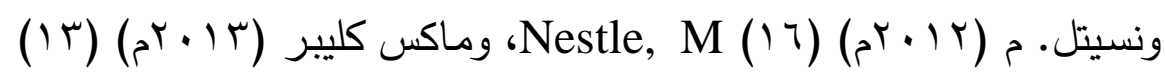
Max Kleiber 
المعادلة (1 calorie = 4.184 joule)، والتي تئكد على العلاقة الطردية بين الكالوري والجـول.أي أنه كلمـا زاد الشـخل المبذول او الطاقـة المبذولة كلمـا زاد معدل استهلاك السعرات الحرارية. وكمـا سبق يمكن القول بأن المتغيرات البيوميكانيكية قيد الدراسـة مـن شـل وطاقة وقدرة يمكن الاستـلال بها على معدل استهلاك الكالوري خـلال النشاط الرياضين وهو ما توضحهه المعادلة (1 calorie = 4.184 joule)،

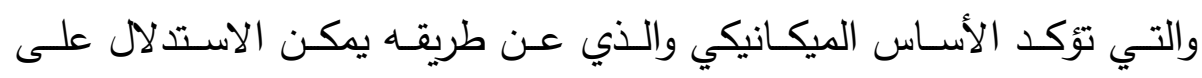
المتغيرات الفسيولوجية مثل معجدل استهلاك السعرات الحرارية. أهمية ومشكلة الاراسة : من خلال عمل الباحث في اختبارات القبول لقسم التربية البدنية وعلوم

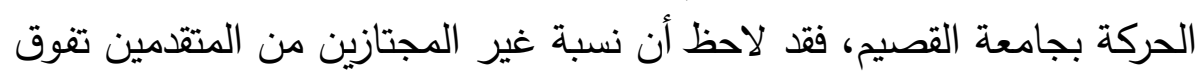

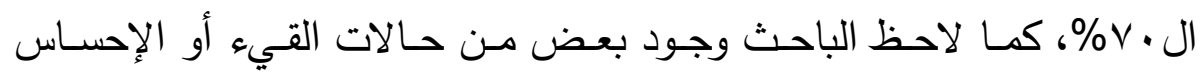
بالدوار للدى بعض المقدمين، ويعزو الباحث ذلك إلى أنه قد يكون النظـام الغذائي الخاطئ والمتبع من بعض المتقدمين و عدم دراية المتقدم بالمجهود

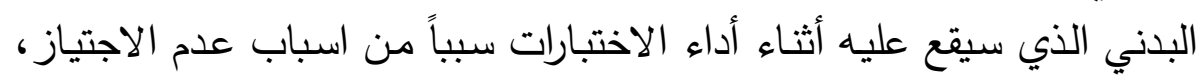
وأنه في حالة المعرفة التامة بالمجهود البدني الذي سيقع على المتقدم قبل البدء في الاختبارات قد يكون له تأثير إيجابياً في إجتياز الاختبارات خاصـة البدنية منها.

تظهر أهميـة الدراسـة في تحديـد السـعرات الحراريـة المطلوبـة لاجتيـاز اختبارات القبول بقسم التربية البدنية وعلوم الحركة، وذلك لإعطاء المتقدمين

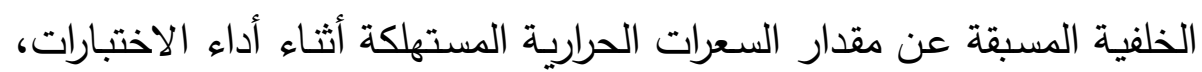
كما تعمل على اعطاء تصور كامل عن فسيولوجيا استهلاك السعرات الحرارية

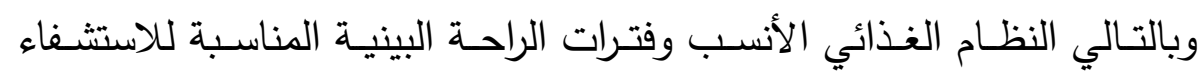
واستعادة النظام الغذائي لقدرته على إنتاج الطاقة المطلوبة. 


\section{rvq}

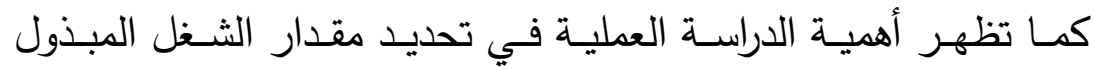
والطاقة والقدرة المبذولة أثناء أداء الاختبارات، مما قد يساعد على إعطاء خلفية كاملة للمتقدم قبل البدء في الإختبارات الخاصـة بالقبول خاصـة البدنية منها،

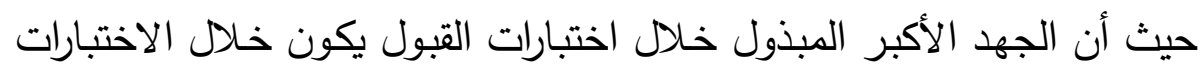

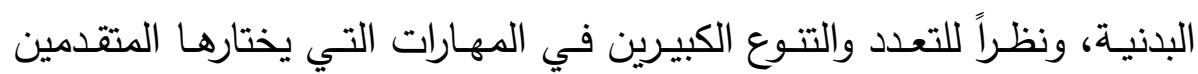
وصـوبة حصـرها، لذا قام الباحث بدراسـة المتغيرات البيوديناميكية والسـعرات الحرارية خلال الاختبارات البدنية دون الوضع في الاعتبار المتغيرات الخاصـة بباقي الاختبارات.

كمــا تعطـي الدراســة صــورة واضـــة عـن المتغيـرات البيوديناميكيـة والسعرات الحرارية التي قد تكون أساساً علمياً لإعادة هيكلة الإختبارات البدنية للقبول في كليات التربية الرياضية وأقسام التربية والبدنية وعلوم الرياضة. أهداف الدراسة: تهدف هذه الاراسة إلى:

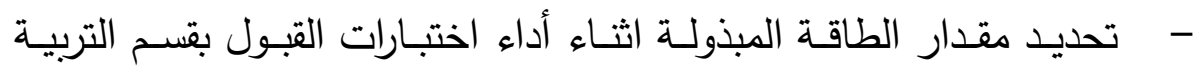

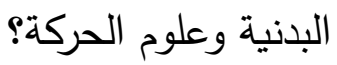
- - تحديد مقدار الشغل المبذول اثناء أداء اختبارات القبول بقسم التربية البدنية

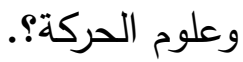
- - - تحديد مقدار القدرة المبذولة اثناء أداء اختبارات القبول بقسم التربية البدنية

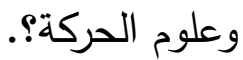
- - تحديد مقدار السعرات الحرارية المستهلكة اثثاء أداء اختبارات القبول بقسم التربية البدنية وعلوم الحركة؟. تساؤلات الدراسة: - - مـا مقدار الطاقة المبذولة اثناء أداء اختبارات القبول بقسم التربية البدنية

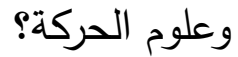


- ما مقدار الثغل المبذول اثناء أداء اختبارات القبول بقسم التربية البدنية

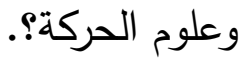

- - مـا مقدار القدرة المبذولة اثناء أداء اختبارات القبول بقسم التربية البدنية

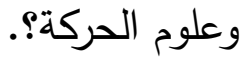
- مـا مقدار السعرات الحراريـة المستهلكة اثنـاء أداء اختبارات القبول بقسم التربية البدنية وعلوم الحركة؟. المصطلحات المستخدمة في الدراسة:

Calorie : السعر الحراري: تعرف بأنها كمية الحرارة اللازمة لرفع درجة حرارة جرام واحد من ماء

$$
\text { الرموز مئوية واحدة. ( ( المستخدمة في الدراسة:) }
$$

\begin{tabular}{|c|c|c|c|}
\hline كجم & $\mathrm{m}$ & Mass & - الكتلة \\
\hline م/ث & $\mathrm{v}$ & Velocity & - السرعة - \\
\hline جول & $\mathrm{KE}$ & Kinetic Energy & - الطاقة الحركية \\
\hline جول & $\mathrm{PE}$ & Potential Energy & - طاقة الوضع \\
\hline نيوتن •م & W & Work & - الشغل - ال - \\
\hline جول/ث & $\mathrm{P}$ & Power & - القدرة \\
\hline كالوري & $\mathrm{Cal}$ & Calories & من - الجراءات الدرات الحرارية \\
\hline
\end{tabular}

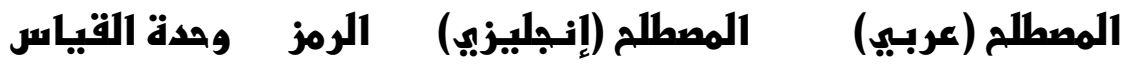

استخدم الباحث المنهج الوصفي باستخدام الأسلوب المسحي لمناسبته

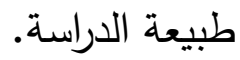


مجتمع وعينة الدراسة:

تم اختيار عينة الدراسة الأساسية بالطريقة العمدية من المتقدمين للقبول

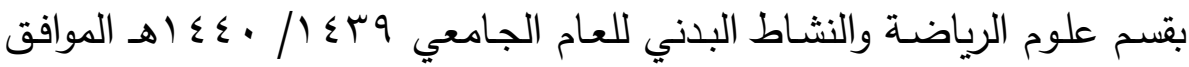

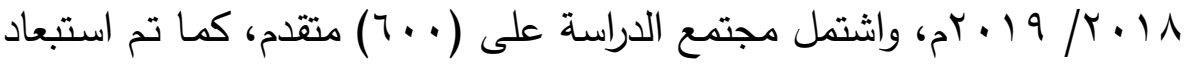

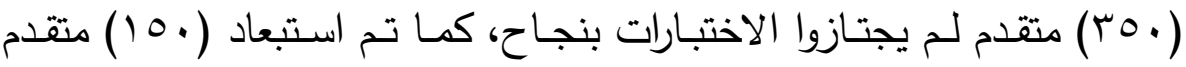
الذين كانت دراجتهم في الاختبارات البدنية أقل من المتوسط، ليصبح عدد عينة الدراسة ( - م ( ) متقدم.

المتوبــط الحسـابي والوسـيط والإنحـراف المعيـاري ومعامـل الالتـواء لعينـة الدراسة :

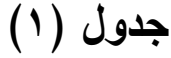

المتوسط الحسابي والوسيط والانحراف المعياري ومعامل الالتواء للعينة قيد

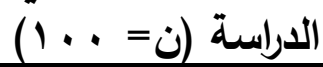

\begin{tabular}{|c|c|c|c|c|c|c|c|}
\hline $\begin{array}{l}\text { معامل } 1 \text { التواء } \\
\text { التوال }\end{array}$ & الوسيط & المعياري الانـمراف & المتوسط & القياسة وحدة & بيانات إهصائية & & م \\
\hline.$\leqslant \vee \mu$ & IVT.. & r.9V & IVT.V & سم & 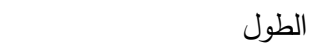 & 1 & \multirow{3}{*}{ معــــلات } \\
\hline $1.7 \varepsilon$ & Tr... & V.乏 & $T \leq .1 T$ & كجم & الوزن & $r$ & \\
\hline r... & $r .17$ & $1 . r T$ & $r r \cdot . \Lambda$ & شهر & السن السن & $r$ & \\
\hline .ros & А... & س & $V .9 T$ & درجة & اختبار العدو •.0م. & 1 & \multirow{6}{*}{ 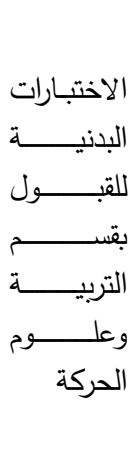 } \\
\hline$\ldots v 1-$ & А... & $1 . \leqslant r$ & $\wedge . \cdot \varepsilon$ & درجة & 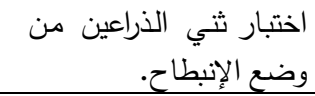 & $r$ & \\
\hline IITH & ^... & .90 & A.Ir & درجة & اختبار الوثب إماماً. & $r$ & \\
\hline..$\leq 79-$ & $9 . .$. & $1 . r \varepsilon$ & $\Lambda . \leqslant \Lambda$ & درجة & بين الأقمار الجــري الزجزاجـى & $\varepsilon$ & \\
\hline .110 & ^... & 1.17 & 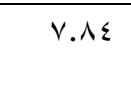 & درجة & الجتبار ثنى الجذع أماماً من & 0 & \\
\hline$. .1 \leq \varepsilon-$ & ^... & $1 . \leqslant 1$ & $\wedge . \cdot \wedge$ & درجة & اختبار الجري · . 'ح. & 7 & \\
\hline
\end{tabular}

يتضـح مـن جدول ( (1) أن قيم معامـل الالتـواء للعينـة قيد الدراسـة قد انحصرت مـا بين (بد) مما يدل على اعتدال المنحنى التكرارى لأفراد عينة الدراسة في هذه المتغيرات. 
وبسائل جمع البيانات :

استخدم الباحث الوسائل التالية لجمع البيانات :

1 - وسائل جمع البيانات الأنثروبومترية.

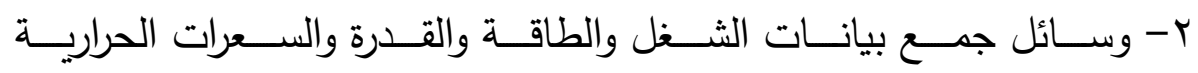

المستهلكة.

r- وسائل جمع البيانات اختبارات القبول بقسم التربية وعلوم الحركة.

وسائل جمع البيانات الأنثروبومتريـة:

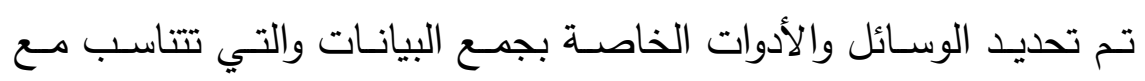

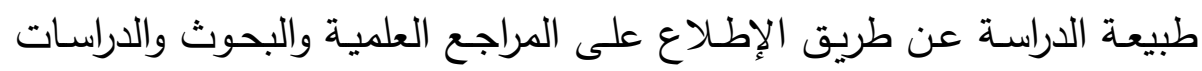

السابقة، وقد قام الباحث باستخدام الاختبارات والمقاييس والأجهزة التالية:

- جهاز الريتاميتر لقياس الطول الكلى للجسم حتى أقرب الفا سم. - جهاز الميزان الطبى لقياس وزن المتقدم حتى اقرب اكجم.

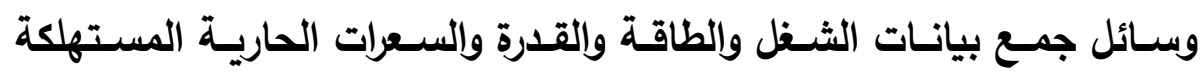
للارراسة :

- التصوير بالفيديو (ثنائي الأبعاد) وذلك باستخدام كاميرا

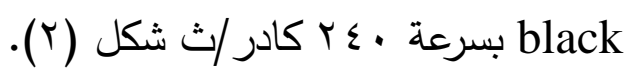

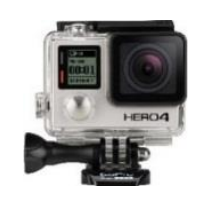

شكل (r)

\section{كاميرا Gopro hero4 black}

نظام التحليل الحركي باستخدام كاميرا الفيديو والحاسب الآلي عن طريق برنـامج Kinovea للتحليل البيوديناميكي، وذلك وفق نموذج التحليل المقترح كما في الشكل (ب). الاختبارات البدنية للقبول بقسم التربية البدنية وعلوم الحركة 


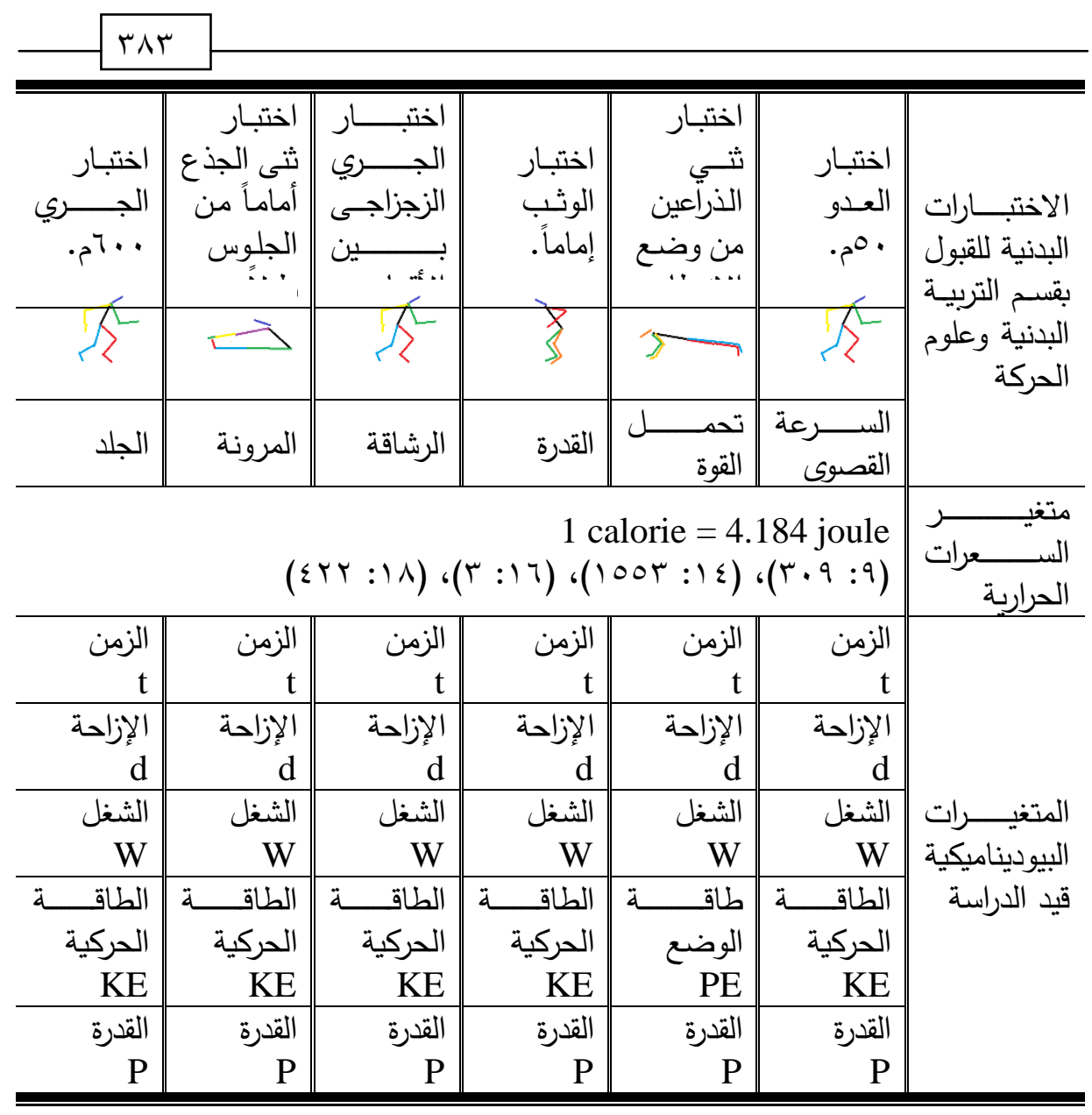

شكل (r)

\section{نموذج التحليل البيوديناميكي للدراسة}

وسائل جمع البيانات لاختبارات القبول بقسم التربية البدنية وعلوم الحركة:

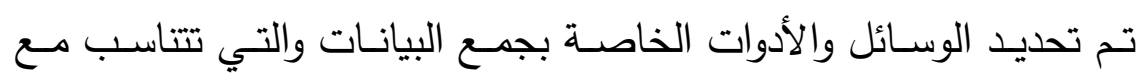
طبيعة الدراسة وهي كالتالي: تصنيل

\section{جدول (ץ)}

وسائل جمع البيانات لاختبارات القبول بقسم التربية البننية وعلوم الحركة مجلة أسيوط لعلوم وفنـون التربية الرياضية 


\begin{tabular}{|c|c|c|c|c|}
\hline الادوات والأبهمزة & المراد قياسنصر & & الاذنتبار & م \\
\hline - - سافرة. & 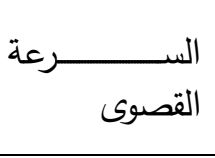 & $\sqrt{2}$ & لار العدو ·0م. & 1 \\
\hline - سافرة. & تحمل القوة & 5 & الإنبطار ثني الذراعين من وضـع & r \\
\hline - رستاميتر • & القدرة & 3 & اختبار الوثب أماماً. & r \\
\hline - & الرشاقة & $\sqrt{2}$ & الأقتماعـار. الجــري الزجزاجــى بــين & $\varepsilon$ \\
\hline - المرونة. & المرونة & 六 & طولاًٍ إخل ثنى الجذع أماماً من الجلوس & 0 \\
\hline - - مضافرة. & الجلد & $\sqrt{2}$ & اختبار الجري · ‘م. & 7 \\
\hline
\end{tabular}

تم اختيار عدد ( • () مسـاعدين من طـلاب قسم التربية البدنية وعلوم

الحركة، وذللك لمساعدة الباحث في تطبيق إجراءات الدراسة. مرفق (9)

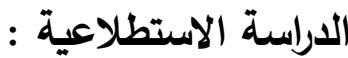

أجرى الباحث دراسة استطلاعية للتعرف على الظروف والمشكلات التي

قد تواجه الباحث أثناء الدراسـة الأساسية وتم تتفيذها في يوم الخميس الموافق

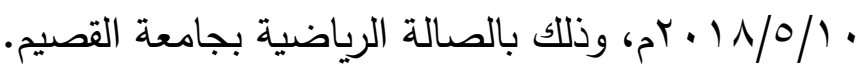

وتم إجراء التجربة الاستطلاعية على عدد (• ( ) من طلاب قسم التربية

البدنية وعلوم الحركة. واستهدفت الدراسة الاستطلاعية التعرف على:

- - - الأبعاد الخاصة بالكاميرا.

- مدى وضوح الرؤية من خلال الكاميرا لتسهيل عملية التحليل فيما بعد.

وقد حقتت الدراسة الاستطلاعية أهدافها.

الاسرة الأساسية : الاسية 
تـم تتفيـذ الدراسـة الأساسـية خـلال الفتـرة مـن يـوم الأربعـاء الموافـق

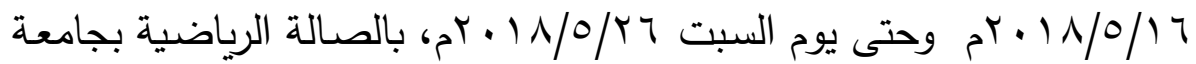

القصيیم

المعالجات الإحصائية :

SPSS ) استخدم الباحث برنامج (الحزمة الإحصائية للعلوم الاجتماعية)

(Statistical Package for Social Science) (20 في معالجة البيانات

إحصائياً باستخدام المعاملات الاحصائية المناسبة للدراسة.

عرض ومناقشة النتائج :

فيما يلي يتم عرض ومناقشة النتائج الخاصـة بالدراسـة وذلك عن طريق

اسـخدام مؤشـر الشـغل والطاقـة والقدرة والسـعرات الحراريـة كمحددات لاجتياز

اختبارات القبول بقسم التربية البدنية وعلوم الحركة بجامعة القصيم، ذلك في

ضـوء البيانـات والنتائج للقياسـات الخاصـة بالمتغيرات قيد الدراسـة علي العينـة واعتماداً على نتائج التحليل الإحصائي التي تتماشى مع طبيعة الدراسة الحالية. وفي ضوء فروض الدراسة سوف يعرض الباحث النتائج التي توصل إليها فيما يلي:

عرض النتائج: - مرئ

1 - عرض البيانـات الخاصـة بمتغير الطاقة المبذولة أثناء أداء الاختبارات البدنية للقبول بقسم التربية البدنية وعلوم الحركة:

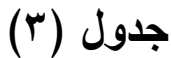

متوسط الطاقة المبذولة أثناء أداء الاختبارات البدنية للقبول بقسم التربية

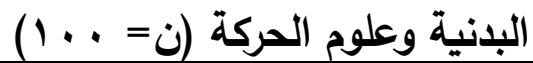

\begin{tabular}{|c|c|c|c|c|}
\hline متوسط الطاقة & العنصر المراد & & الافتبار & م \\
\hline عـ.بrه اجول & القصـى الســـــرعة & $\sqrt{2}$ & اختبار العدو ••م. & 1 \\
\hline
\end{tabular}

تابع جدول (r) 
ए人т

متوبط الطاقة المبذولة أثناء أداء الاختبارات البدنية للقبول بقسم التربية

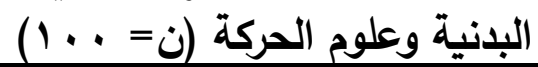

\begin{tabular}{|c|c|c|c|c|}
\hline متوسط الطاقة & العنصر المراد & \multicolumn{2}{|r|}{ 1اذنتبار } & م \\
\hline 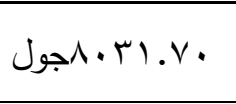 & تحمل القوة & 5 & الإنبطار ثني الذراعين من وضـع & r \\
\hline 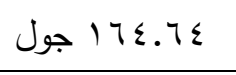 & 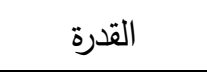 & 3 & اختبار الوثب أماماً. & r \\
\hline ا & الرشاقة & $L^{2}$ & اختبار الجري الزجزاجى بين الأقماع. & $\varepsilon$ \\
\hline ا & 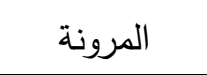 & > & اختبار ثنى الجذع أماماً من الجلوس طولاً. & 0 \\
\hline 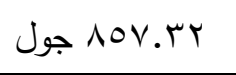 & 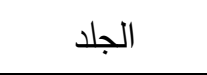 & $2^{2}$ & اختبار الجري · · جم. & 7 \\
\hline ד.V.1. & & & الإجمالى & \\
\hline
\end{tabular}

يتضح من جدول (r) قيم الطاقة المبذولة أثناء أداء الاختبارات البدنية

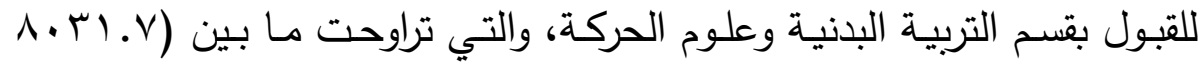
جول) لاختبار تحمل القوة، وما بين (11 (1) . •جول) لاختبار المرونة، وكانت

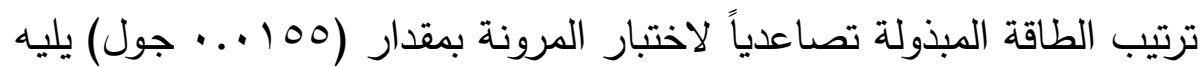

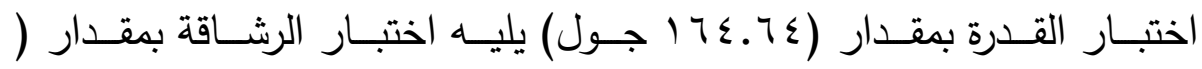
(Y.Y.Y

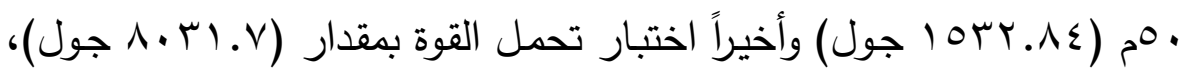

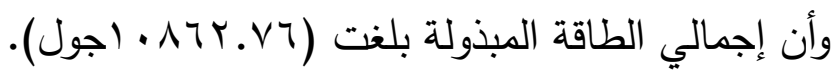

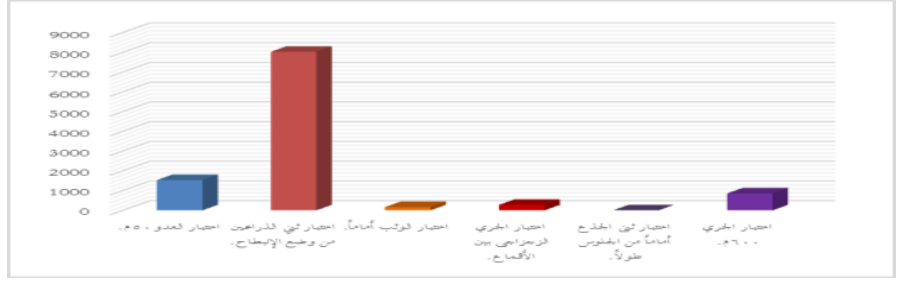

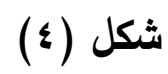

متوبط الطاقة المبذولة أثناء أداء الاختبارات البدنية للقبول بقسم التربية

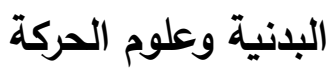


ץ - عرض البيانـات الخاصـة بمتغير الثـخل المبذول أثنـاء أداء الاختبـارات البدنية للقبول بقسم التربية البدنية وعلوم الحركة:

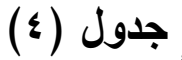

متوبط الشغل المبذول أثناء أداء الاختبارات البذنية للقبول بقسم التربية

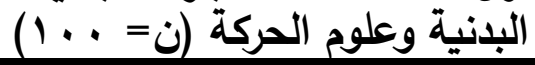

\begin{tabular}{|c|c|c|c|c|}
\hline متوسط & العنصر المراد & & الافتبـار & \\
\hline ا & السرعة القصوى & & اختبار العدو •مم. & 1 \\
\hline ( & تحمل القوة & s- & اختبار ثنى الذراعين من وضع الإنبطاح. & $r$ \\
\hline 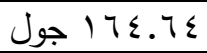 & 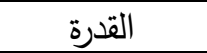 & & اختبار الوثب أماماً. & $\mu$ \\
\hline Tو TVY.YI & 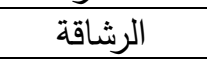 & & اختبار الجري الزجزاجى بين الأقماع. & $\varepsilon$ \\
\hline ا & 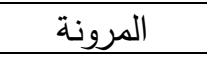 & 8 & اختبار ثنى الجذع أماماً من الجلوس طولاً. & 0 \\
\hline ا & الجلد & 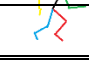 & اختبار الجري ...7م. & 7 \\
\hline ا & & & 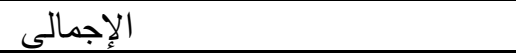 & \\
\hline
\end{tabular}

يتضـح من جدول (ع) قيم الثخل المبذول أثناء أداء الاختبارات البدنية

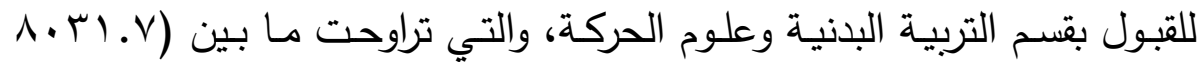

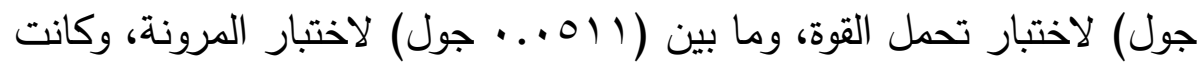

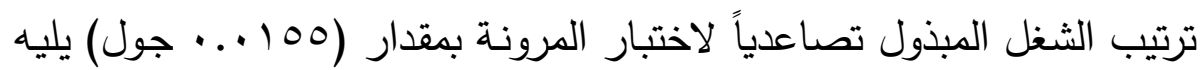

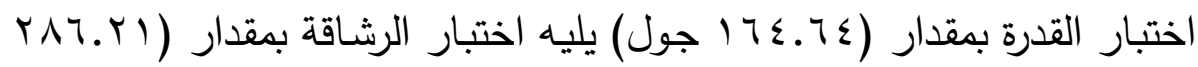

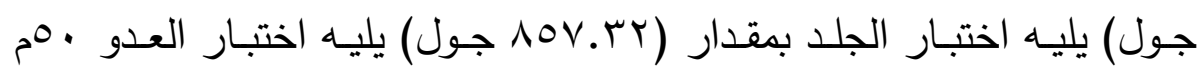

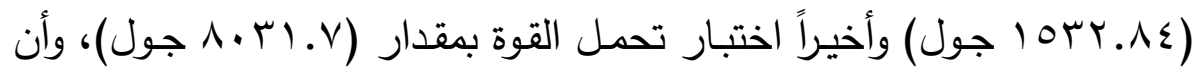

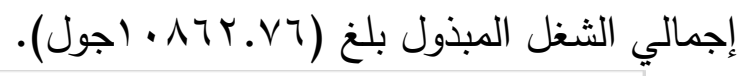

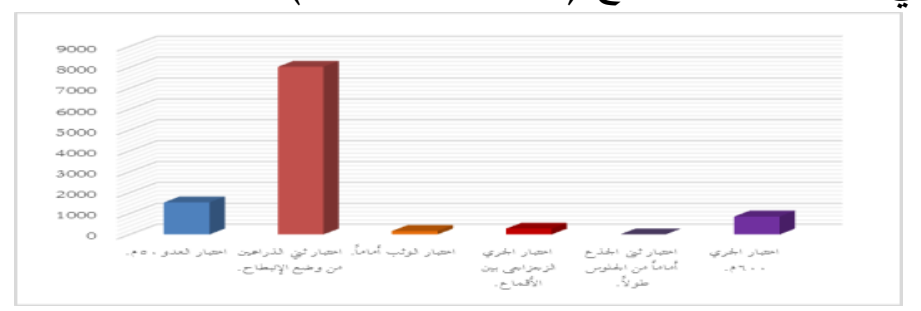

شكل (0)

متوسط الشغل المبذول أثناء أداء الاختبارات البدنية للقبول بقسم التربية البدنية وعلوم الحركة الاعتاء الباء 
ب- عـرض البيانـات الخاصـة بمتغيـر القـدرة أثنـاء أداء الاختبـارات البدنيـة للقبول بقسم التربية البدنية وعلوم الحركة:

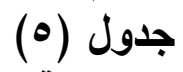

متوسط القدرة أثناء أداء الاختبارات البدنية للقبول بقدم التربية البدنية وعلوم

\begin{tabular}{|c|c|c|c|c|}
\hline متوسط & المراد قياسته & & الافتبار & \\
\hline 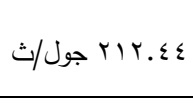 & 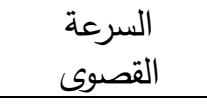 & $\sqrt{2}$ & اختبار العدو •0م. & 1 \\
\hline 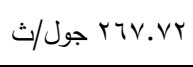 & تحمل القوة & 5 & اختبار ثي الذراعين من وضح الإنبطاح. & r \\
\hline 19.7rا جول/ث & 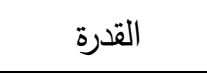 & 3 & اختبار الوثب أماماً. & r \\
\hline ك & 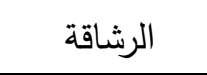 & 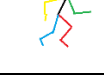 & اختبار الجري الزجزاجى بين الأقماع. & $\varepsilon$ \\
\hline | & المرونة & خ & طولاً. إنبار ثنى الجذع أماماً من الجلوس & 0 \\
\hline ا & 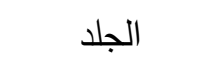 & $\sqrt{2}$ & اختبار الجري . . דم. & 7 \\
\hline ا. & & & الإجمالي & \\
\hline
\end{tabular}

يتضـح من جدول (0) قيم القدرة المبذولة أثناء أداء الاختبارات البدنية

للقبول بقسم التربية البدنية وعلوم الحركة، والتي تراوحت مـا بين (Y.VY. جول/ث) لاختبار تحمل القوة، وما بين (11 (101. . جول/ث) لاختبار المرونة،

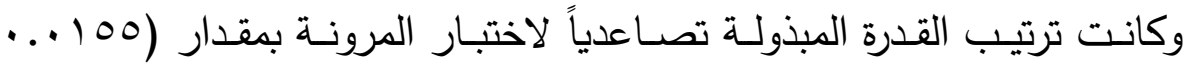

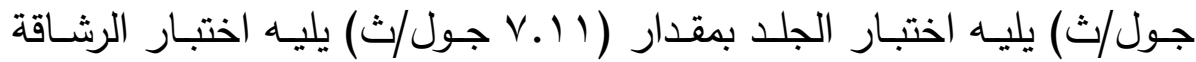

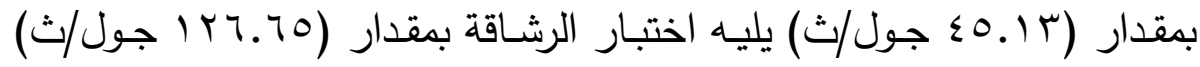

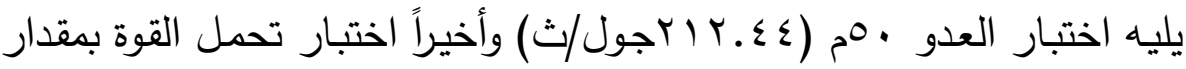

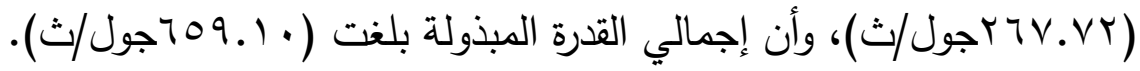




\section{شكل (7)}

متوسط القدرة أثناء أداء الاختبارات البدنية للقبول بقسم التربية البدنية وعلوم

$$
\text { الحركة }
$$

ع - عرض البيانات الخاصة بمتغير السـعرات الحراربـة المستهلكة أثناء أداء

الاختبارات البدنية للقبول بقسم التربية البدنية وعلوم الحركة:

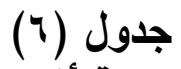

متوبط السعرات الحرارية المستهلكة أثناء أداء الاختبارات البدنية للقبول

\begin{tabular}{|c|c|c|c|c|}
\hline متوسطالسعرات & قالعنصر المراد & \multicolumn{2}{|r|}{ 1لاذغتبار } & م \\
\hline هـ.ד דسكلوري & القصوى السعة & $\sqrt{2}$ & اختبار العدو • مم. & 1 \\
\hline 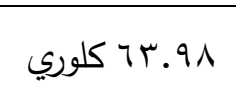 & تحمل القوة & 5 & الإنبطارح. ثي الذراعين من وضـع & $r$ \\
\hline 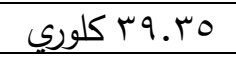 & القدرة & $\alpha$ & اختبار الوثب أماماً. & $r$ \\
\hline 10 1.77 كلوري & الرشاقة & $R$ & اختبار الجري الزجزاجى بين الأقماع. & $\varepsilon$ \\
\hline r r •... كلوري & المرونة & 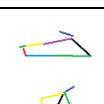 & طولاًٍ إخى الجذع أماماً من الجلوس & 0 \\
\hline .9. . . . كلوري & الجلد & 2 & اختبار الجري . . آم. & 7 \\
\hline 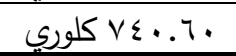 & & & الإجمالى & \\
\hline
\end{tabular}

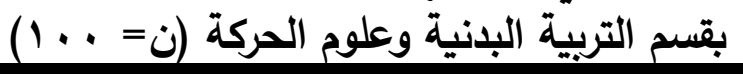

يتضـح مـن جـدول (7) قيم السـعرات الحراريـة المسـتهلكة أثنـاء أداء

الاختبارات البدنية للقبول بقسم التربية البدنية وعلوم الحركة، والتي تراوحت ما

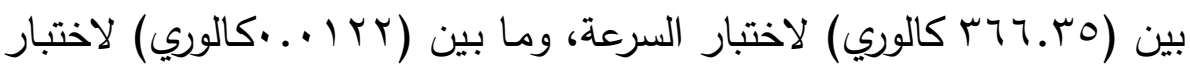
المرونة، وكانت ترتيب السعرات الحراريـة المستهلكة تصـاعدياً لاختبار المرونـة لإنة

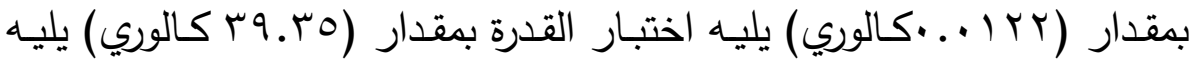
اختبـار تحمـل القـوة بمقـدار (19.باكــالوري) يليـهـ اختبـار الرشـاقة بمقـدار

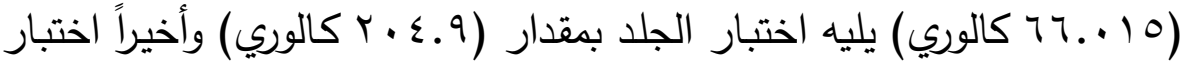


$r q$.

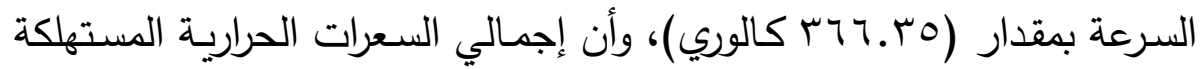

$$
\text { بلغت (.7. • ك كلوري). }
$$

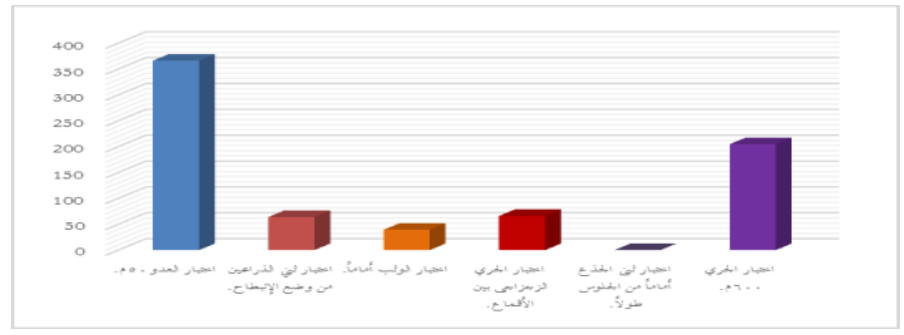

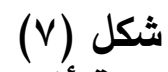

متوبط السعرات الحرارية المستهلكة أثناء أداء الاختبارات البذنية للقبول

$$
\text { بقسم التربية البلنية وعلوم الحركة المبلة أداء الأبات }
$$

ه - عرض البيانـات للمتغيـرات قيــ الدراسـة أثنـاء أداء الاختبـارات البدنيـة البهة

للقبول بقسم التربية البدنية وعلوم الحركة:

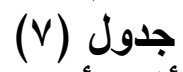

\begin{tabular}{|c|c|c|c|c|c|c|c|c|}
\hline الإجمالي & افتبار & 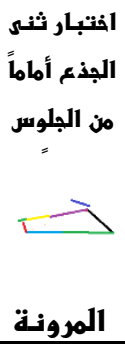 & الزتبار الجري & 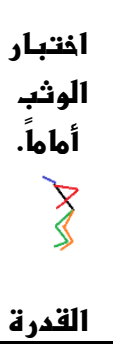 & الذراعين من & العدم. & \multicolumn{2}{|c|}{ 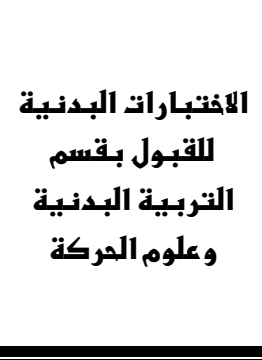 } \\
\hline 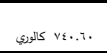 & $r . \Sigma . q$. &.. $.1 r r$ & $77 .+10$ & r9.r4 & Tr.91 & ס & \multicolumn{2}{|c|}{ السعرات الحرارية المستهلكة } \\
\hline 每 & NOV.rT &. .0011 & TVT.rI & $17 \varepsilon .7 \varepsilon$ & A.MI.V. & DOT.AE & الطاقة & المتغيـــــرات \\
\hline 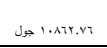 & Nov.rt &. .011 & TVY.rI & $17 \leqslant .7 \leqslant$ & A.r..V. & DOTY.AE & الشغل & البيوديناميكية \\
\hline الم 109.1. & V.11 &. .0011 & $\varepsilon 0.1 \mu$ & $1 \times 7.70$ & YTV.VT & rM. & القدرة & قيد الدراسة \\
\hline
\end{tabular}

متوسط المتغيرات قيد الدراسة أثناء أداء الاختبارات البدنية للقبول بقسم

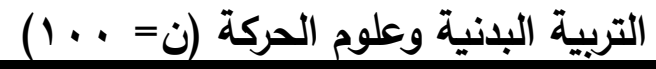

يتضـح مسن جدول (V) قيم

متغيـرات الدراســـة البيوديناميكيــة

والسـعرات الحراريـة المستهلكة أثناء

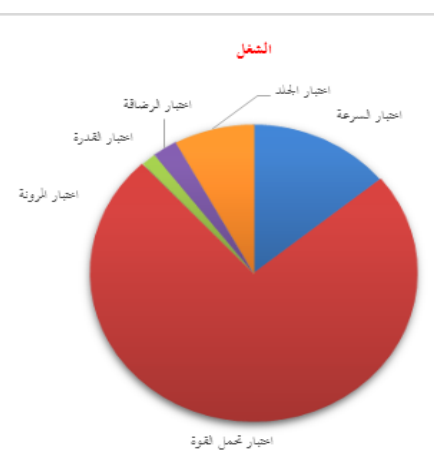




\section{pql}

أداء الاختبارات البدنية للقبول بقسم التربية البدنية وعلوم الحركة.

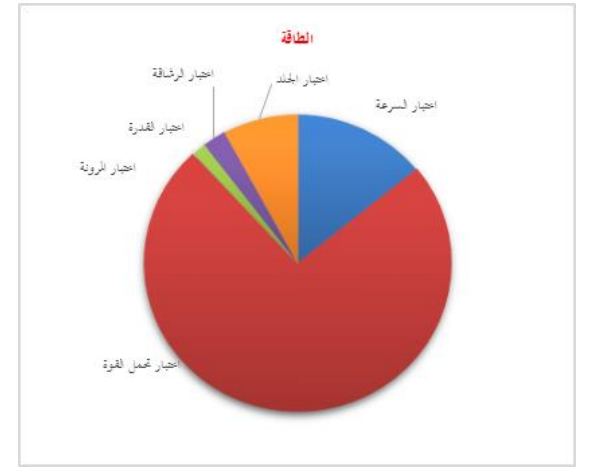

شكل (^)

متوبط المتغيرات قيد الدراسة أثناء

أداء الاختبارات البدنية للقبول بقسم

التربية البدنية وعلوم الحركة

مناقثة النتائج :

مناقشة نتائج التساؤل الأول :
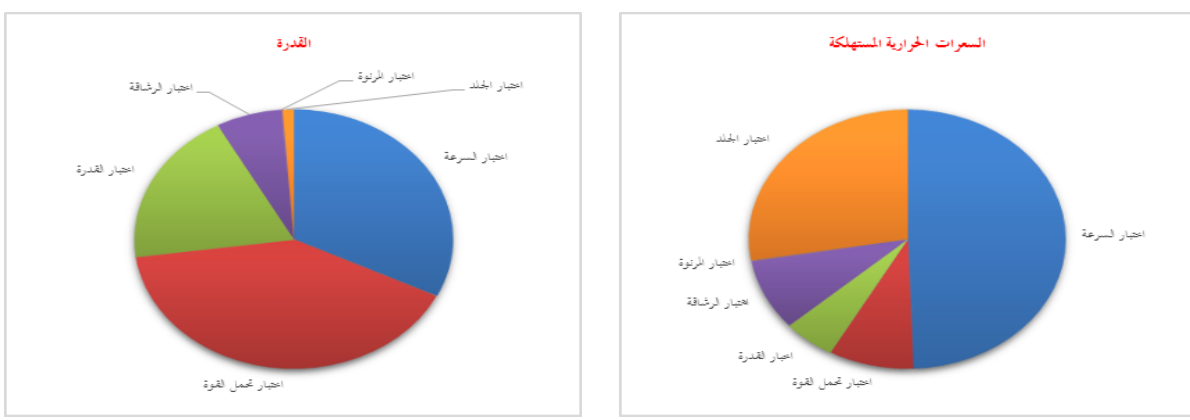

والذي ينص على أنـه " مامقدار الطاقـة المبذولـة اثـاء أداء اختبـارت

القبول بقسم التربية البدنية وعلوم الحركة؟.".

يتضح من جدول (ب) مقدار الطقة المبذولة أثناء أداء الاختبارات البدنية

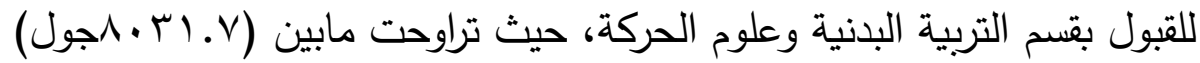
لاختبار تحمل القوة، ومابين (11 (10 . •جول) لاختبار المرونة، وكانت ترتيب

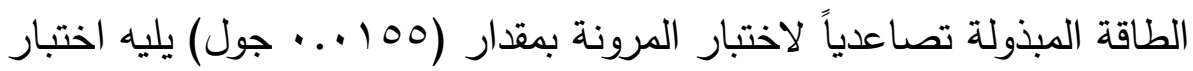

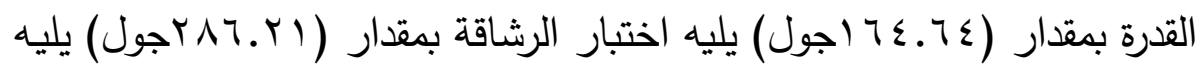

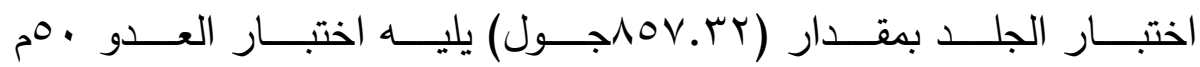

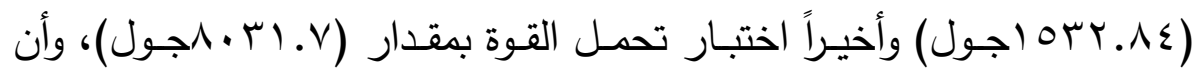

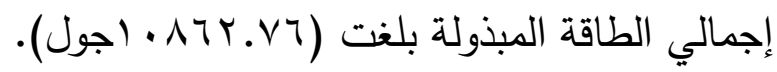




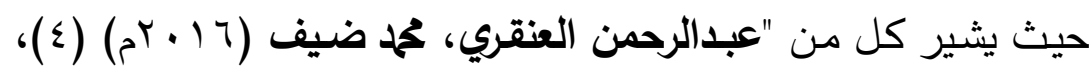

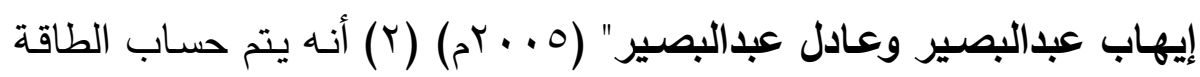

$$
\begin{aligned}
& \text { الحركية عن طريق معادلة ( })=\frac{1}{2} m \cdot v^{2} \text { ) } \\
& \text { حيث أن: } \\
& \text { KE } \\
& \text { = } \\
& \text { = vرعة اللاعب }
\end{aligned}
$$

وهو ماتم تطبيقه في اختبار السرعة، القدرة، الرشاقة، المرونة والجلد. كما أنه يتم حساب طاقة الوضع عن طريق المعادلة ( حيث أن:

SE =

g

هx وهو ماتم تطبيقه في اختبار تحمل القوة.

ويعزي الباحث ذلك إلى أن الطاقة ترتبط ارتباطاً مباشراً بالسرعة، لذات

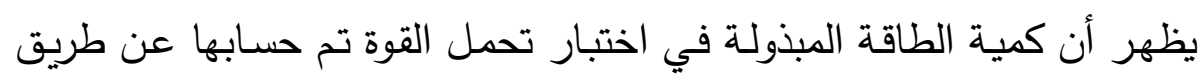
حسـاب طاقة الوضـع PE وقسمتها على الزمن، ممـا سبب في زئه زيـادة الطاقة المبذولة خلال فترة • ساث وهي زمن أداء الاختبار •

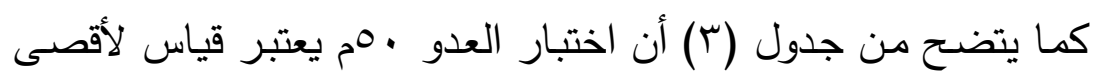
سرعة انتقالية للمتقدم، لذا فقد احتلت المركز الثاني في معدل الطاقة المبذولة

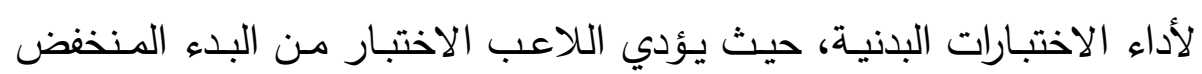
ويستمر في الجري بشكل خطي مستقيم حتى خط النهايـة دون أي تغيير في اتجاه الحركة وبالتالي دون فقد في الطاقة المبذولة. 
كما يتضح من جدول (r) في اختبار الجلد أن كمية الطاقة المبذولة

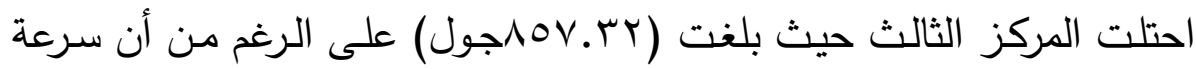

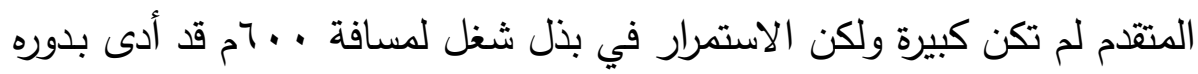
إلى الزيادة في الطاقة المبذولة أثناء الاختبار .

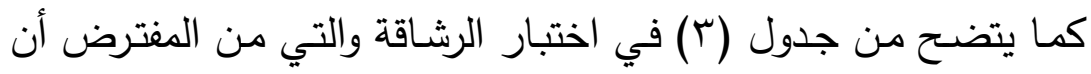
يؤديها اللاعب بأقصى سرعة أن هناك تتاقص كبير في الطاقة المبذولة لأداء

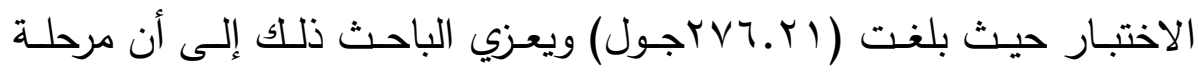

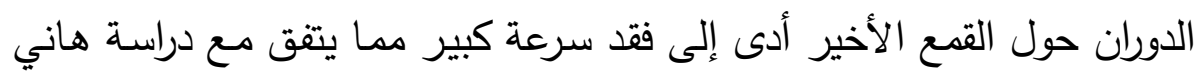

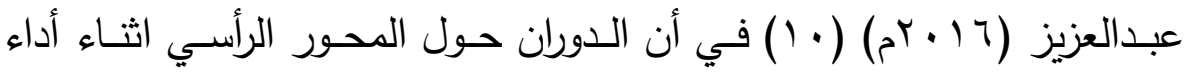

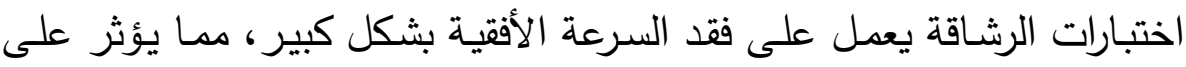
درجة الاختبار وعلى المتغيرات البيوديناميكية المحسوبة.

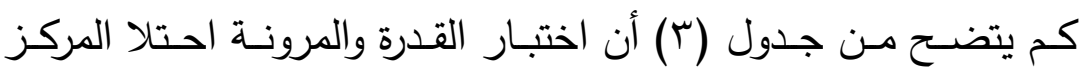

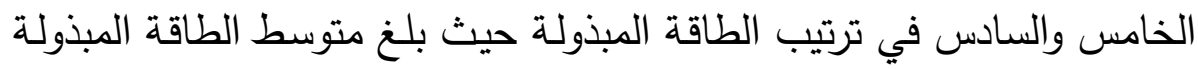

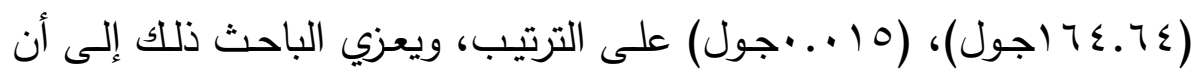

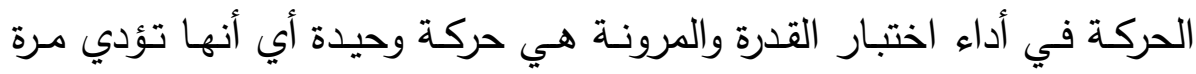
واحدة فقط على عكس الاختبارات السابقة بإنها إما حركة متكررة مثل اختبار السرعة، الجلد وتحمل القوة، أو أنها مركبة مثل اختبار الرشاقة.

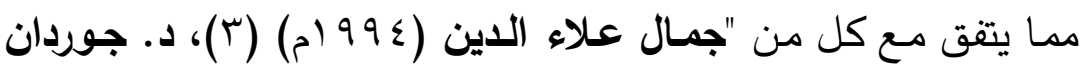

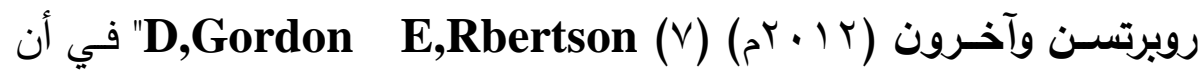

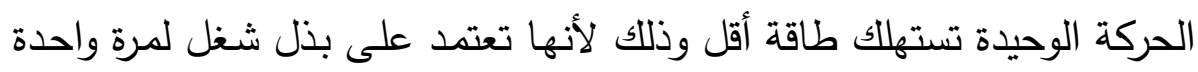

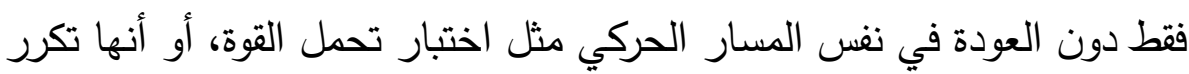
نفس شكل الأداء أكثر من مرة مثل اختبار السرعة والجلد.

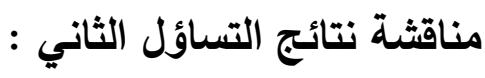


والذي يـص على أنسه " مامقدار الثـخل المبذول اثنـاء أداء اختبـارت القبول بقسم التربية البدنية وعلوم الحركة؟.". يتضـح مـن جـدول (ب)، (ع) تطـابق مقـدار الشــل المبـذول والطاقـة المبذولة، ويعزو الباحث ذللك إلى أنه تعتبر الطاقة هي القدرة على بذل شغل،

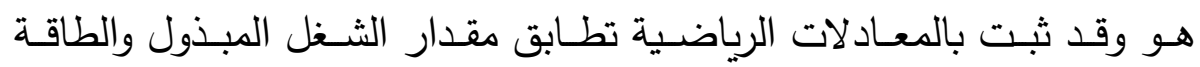
المبذولة سواء في حالات الطاقة الحركية أو طاقة الوضع.

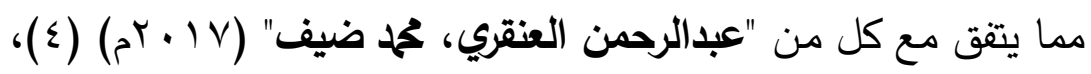

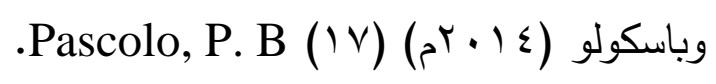

مناقشة نتائج التساؤل الثالث :

والذي ينص على أنه " مامقدار القدرة المبذول اثناء أداء اختبارت القبول

$$
\text { بقسم التربية البدنية وعلوم الحركة؟.". }
$$

يتضح من نتائج جدول (0) أن كل من اختبار تحمل القوة والسرعة قد

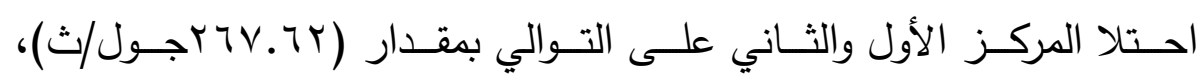

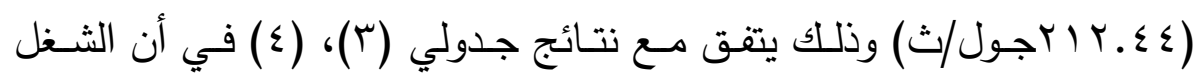
والطاقة المبذولة كانتا في أقصى حد لهما أثتاء أداء اختبار تحمل القوة يليه اختبار السرعة. ويعزو الباحث ذلك إلى أن هذان الاختباران يتطلبان أداء أقصى سرعة

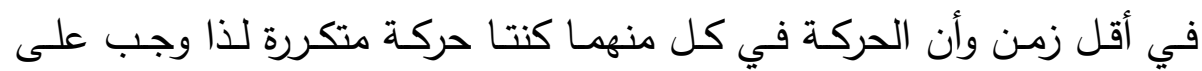
المختبر أن يؤدي أقصى قدرة يمتلكها لاختياز هذان الاختباران.

$$
\begin{array}{r}
\left(P=\frac{W}{\Delta t}\right) \text { حيث يتم حساب القدرة عن طريق المعادلة }=\mathrm{P} \\
\text { القدرة }=\mathrm{W} \\
\text { الشغل }=\mathrm{t}
\end{array}
$$


كمـا يتضـح من جدول (0) أن اختبار القدرة قد احتل المركز الثالث بمقدار (70.70 اجول/ث)، ويعزو الباحث ذللك إلى أن مقدار الثغل المبذول

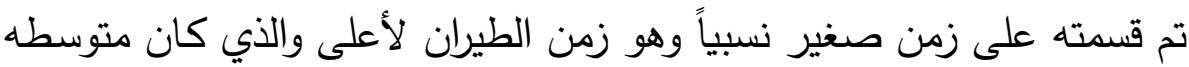
حوالي (r. اث)، مما عمل على ارتفاع القدرة الخاصة بأداء هذا الاختبار. كما يتضح من جدول (0) أن كل من اختبار الرشاقة قد احتل المركز

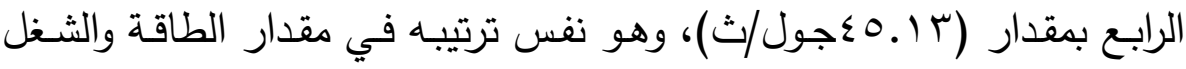

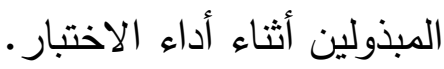
ويعزو الباحث ذلك إلى أن فقد السرعة الذي تم التتويه عنه في مناقشة التهاه

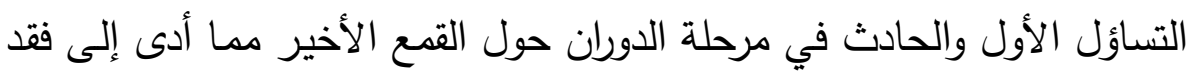
سرعة كبير ، مما يؤثر بدوره على درجة الاختبار وعلى المتغيرات البيوديناميكية

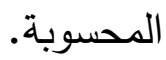
كما يتضح من جدول (0) أن مقدار القدرة المبولة في اختبار الجلد قد أندا

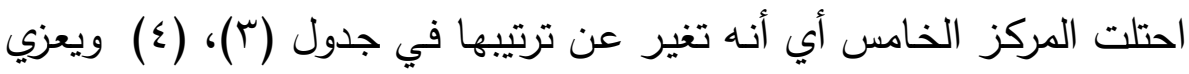

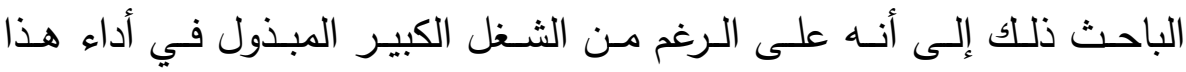

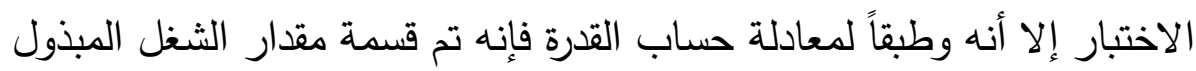

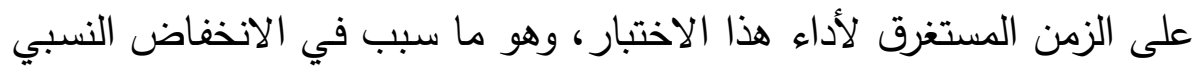
في مقدار القدرة المبذول. كما يتضح من جدول (0) أن اختبار المرونة قد احتل المركز السادس

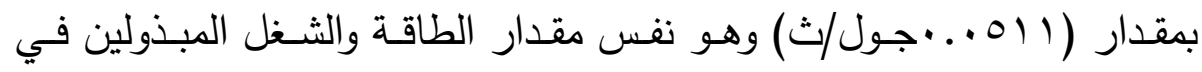

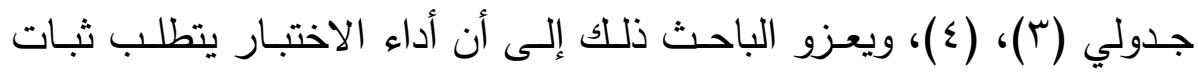
المختبر في وضع أقصى مرونة لمدة (اث) وبقسمة الشغل والطاقة المبذولين على (اث) فإنه عطينا نفس القيمة للشغل والطاقة. 


\section{مناقثة نتائج التساؤل الرابع :}

والذي ينص على أنه " مامقدار السعرات الحراريـة المستهلكة اثناء أداء

$$
\text { اختبارت القبول بقسم التربية البدنية وعلوم الحركة؟.". }
$$

يتضـح من نتائج جدول (T) أن السعرات الحراريـة المستهلكة أثناء أداء

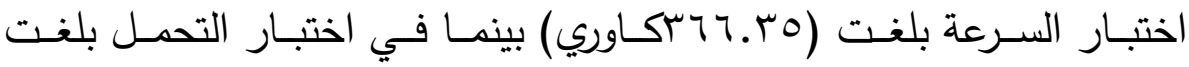
(9.ـ • بكالوري) ويعزو الباحث ذللك إلى أن الجسم خلال أداء اختبار السرعة يعتمد على نوعين من أنظمة انتاج الطاقة اللاهوائي (Anaerobic system) وهما:

- - استهلاك ال ATP المباشر الموجود بالعضلات.

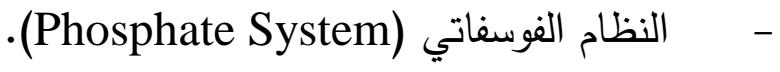
- - مظام حض اللاكتيك (Lactic Acid System). ولكنه لايتنقل للنظام الأكسجيني والذي يعتمد على الأكسوجين في انتاج الطاقة وذلك بسبب أن الاختبار لايستمر أكثر من (9ث)، الأمر الذي يؤدي إلى انتاج سعرات حرارية سريعة واستهلاكها أيضاً بشكل سريع.

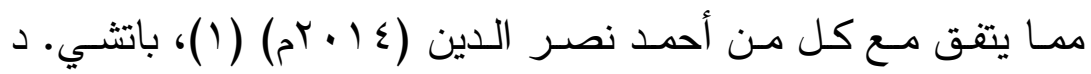
، (9) Haff, G.) Bauchi

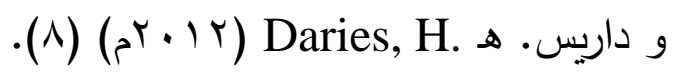

(Adenosine Triphosphate) ATP حيث أن نظامي انتاج ال اللاهوائي هو المصدر الأول للطاقة بالجسم وذللك حتى حيث يتم استهلاك ال

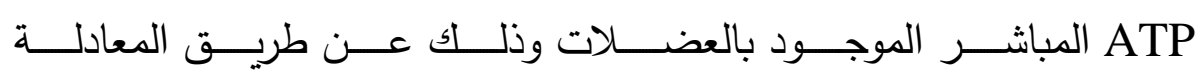
(ATP $\rightarrow$ Adp + Pi + Energy $)$ 
ومن ثم ينتقل الجسم إلى النظام التالي من نظم انتاج الطاقة وهو تكوين

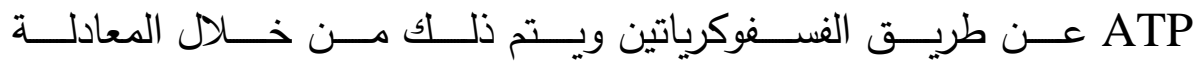
(ADP + PC $\rightarrow$ ATP + C $)$ العضلي، ويتميز هذا النظام بالسرعة الكبيرة في انتاج ال ATP اللازم لامداد الجسم بالطاقة اللازمـة لـأداء الحركين ولكن من عيوب هذا النظام استهلاكك كمية كبيرة من الجليكوجين لانتاج ال ATP حيث أنه يستهلك الجسم حوالي ( • (جرام) مـن الجليكوجين لانتاج (سمول مـ ATP). وهذ مـا سبب في استهالك كمية من الكالوري أكبر منها في اختبار الجلد. وذلك على العكس في اختبار التحمل والذي يستمر حوالي (•r أث) Lactic ～وبالتالي فإن الجسم يعتمد في انتاج الطاقة على نظام اللاكتيلك Acid System وهو نظام ينتج سعرات حراريـة كبيرة جداً ولكنها تستهلك ببطء، فعن طريق ذلك النظام يستطيع جزيـ جليكوجين كامل أن ينتج حوال (q مول من ال ATP). ويعيب هذا النظام ظهور التعب نتيجة تراكم حمض الاكتيك في العضـلات، مما قد يسبب إلى تناقص سرعة اللاعب وهو مايؤثر فـي الطاقــة المبذولــة حيــث يـتم حسـاب الطاقــة عــن طريـق المعادلــة

$$
\cdot\left(K E=\frac{1}{2} m \cdot v^{2}\right)
$$

وهذا يعني أن تراكم حمض اللاكتيك الناتج عن انتقال الجسم إلى نظام حمـض اللاكتيـك لانتـاج الطاقـة قـد سـبب تتـاقص الطاقـة المبذولـة والثــل المبذول، وبالتالي أدى هذا بدوره إلى تتاقص السعرات الحرارية المستهلكة وذلك وفقاً للمعادلة (1 calorie = 4.184 joule) والتي توضح العلاقة الطردية بين الجول والكالوري.

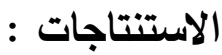


في حدود أهداف الدراسة وفروضها والبيانات المستخدمة والنتائج التي تم عرضها، يستتتج الباحث الآتي: - - إجمالي المستهلك من السعرات الحرارية في الاختبارات البدنية القبول بقسم التربية البدنية وعلوم الحركة بجامعة القصيم حوالي ( • V كالوري) - - مإلي الشغل المبذول والطاقة المبذولة في الاختبارات البدنية القبول بقسم

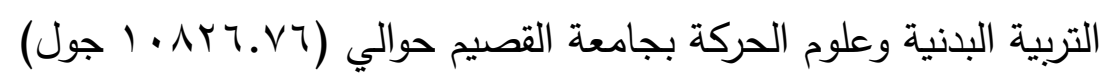
- - إجمالي القدرة المبذولة في الاختبارات البدنية القبول بقسم التربية البدنية وعلوم الحركة بجامعة القصيم حوالي ( • . 709 جول/ث)

- - يتم ترتيب الاختبارات البدنية وفقاً لاستهلاك السعرات الحرارية كالتالي:

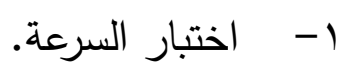

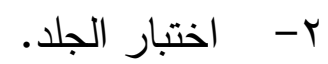
ب- اختبار الرشاقة. ع - اختبار تحمل القوة. 0- - - اختبار القدرة. 7- - اختبار المرونة.

يتم ترتيب الاختبارات البذنية وفقاً للشغل المبذول والطاقة المبذولة كالتالي:

$$
\text { ץ }
$$


צ- - - - اختبار المرونة.

يتم ترتيب الاختبارات البدنية وفقاً للقدرة المبذولة كالتالي:

$$
\text { ז }
$$

\section{التوصيات:}

في ضوء ما أسفرت عنه نتائج الدراسة يوصي الباحث بما يلي:

- إجـراء دراسـات للمقارنـة بين اختبارات القبـول بـين كليـات وأقسـام التربيـة البدنية بالمملكة.

- - إجراء دراسـات على اختبارات القبول بين الكليات العالمية وفق تصنيف شانجهاي والمقارنة بينها وبين الجامعات العربية. - - إعادة تصميم اختبارات القبول في مجال التربية الرياضية مع الوضـع في الاعتبار المتغيرات قيد الدراسة.

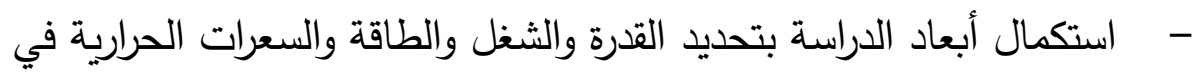
الاختبارات المهارية.

- عمل برنامج تدريبي تأهيلي مبني على نتائج الدراسة للمتقدمين لاختبارات القبول بكليات وأقسام التربية البدنية. 
- - إعطاء فترات راحة بينية بين الاختبارات تتناسب مـع الكم المستهلك من السعرات الحراريـة للاستشفاء واستعادة قدرة نظـام انتاج الطاقة المستخدم في الاختبار التالي. - - إعطلاء نصـائح غذائيسة قبـل التقدم لاختبـارات القبـول مبنيـة على نتـائج الدراسة في متغير السعرات الحرارية المستهلكة.

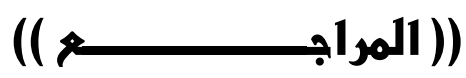

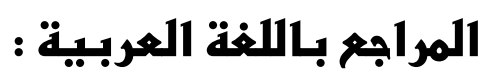

1- أحمــ نصـرالاين: ع 1 ـ بم، مبـادئ فسـيولوجيا الرياضـة، مركز الكتـاب الحديث، طا الق، القاهرة.

ץ- إيهاب عبد البصير، عادل عبد البصير: 0 . . بم، "التحليل البيوميكانيكي

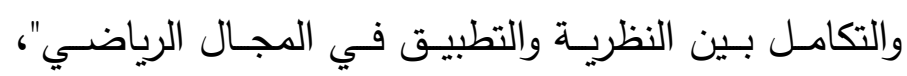
المتحدة للطباعة والتصوير ، بورسعيد.

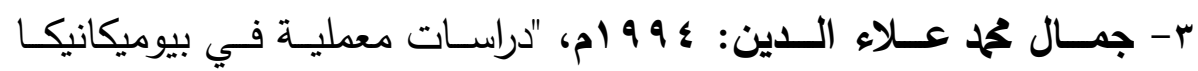
الحركات الرياضية"، طس، دار المعارف، الإسكندرية.

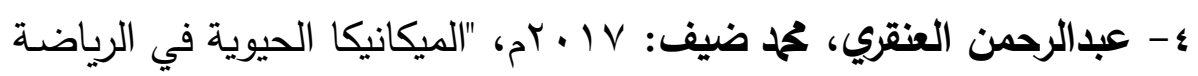
والنشاط البدني"، دار جامعة الملك سعود للنشر ، المملكة العربية السعودية.

\section{نانباً: المراجم باللغة الإنبهليزبة :}

5- Bagchi, D., Nair, S., \& Sen, C. K. (2013). Nutrition and enhanced sports performance: Muscle building, endurance, and strength (1st ed.). US: Academic Press.

6- Bagchi, D., Nair, S., \& Sen, C. K. (2013). Nutrition and enhanced sports performance: Muscle 
building, endurance, and strength (1st ed.).

US: Academic Press.

7- Bartlett, R. (2007). Introduction to sports biomechanics: Analyzing human movement patterns. London: Taylor and Francis. doi:10.4324/9780203462027

8- Bartlett, R., \& Payton, C. (2007; 2008;). Biomechanical evaluation of movement in sport and exercise: The British association of sport and exercise sciences guidelines. England; United Kingdom; Routledge.

9- D,Gordon E,Rbertson, Gary kamen, Graham E,Caldwell, Joseph Hamil, SaundersN,Whittlesey: 2004, : Research Methods in Biomechanics, Human Kinetics publisher ; Champaign

10- Daries, H. (2012). Nutrition for sport and exercise: A practical guide (1st ed.). GB: WileyBlackwell.

11- Haff, G. G., Antoni, J., Greenwood, M., Kalman, D., Stout, J. R., \& Willoughby, D. S. (2008). Essentials of sports nutrition and supplements (1. Aufl. ed.) Humana Press.

12- Hany Abdul Aziz Saleh. (2016). Speed loss analysis during Illinois agility run test in light of 
some Bio-kinematics parameters, Assiut Journal of Sport Science and Arts, Vol. 3

13- Knudson, D. (2007). Fundamentals of biomechanics. Boston: Springer.

14- Kreider, R., Bendich, A., Antonio, J., Kalman, D., Willoughby, D. S., Haff, G. G., Greenwood, M. (2009; 2008;). Essentials of sports nutrition and supplements. Totowa, NJ: Humana Press. doi:10.1007/978-159745-302-8

15- Max Kleiber. (2013). Calories and Joules, Journal of nutrition, United State of America.

16- McTiernan, A. (2010;2011;2014;). Physical activity, dietary calorie restriction, and cancer (1st ed.). New York, NY: Springer. doi:10.1007/978-1-4419-7551-5

17- Medical biochemistry E-book (2018). (Fifth ed.). GB: Elsevier.

18- Nestle, M., \& Nesheim, M. (2012). Why calories count: From science to politics (1st ed.). Berkeley: University of California Press. doi:10.1525/j. ctt7zw2qr

19- Pascolo, P. B. (2014). Biomechanics and sports: Proceedings of the XI winter universals 2003. Vienna: Springer Wien. 


\section{$\varepsilon \cdot r$}

20- W. W. HAWKINS. (2013). The Calorie, The Joule,

Canadian Journals of Research, National

Research Council of Canada, Ottawa,

Canada K1A OR6 